\title{
The effect of stump ligation techniques on operative time in laparoscopic appendectomy
}

Nizamettin Kutluer ${ }^{1}$, Ali Aksuํ, Ulaş Aday², Hakan Burhan Kanat ${ }^{3}$, Abdullah Böyük ${ }^{4}$, Serhat Doğan ${ }^{3}$

${ }^{1}$ Department of General Surgery, Private Doğu Anadolu Hospital, Elazığ, Turkey ${ }^{2}$ Department of General Surgery, School of Medicine, Dicle University, Diyarbakir, Turkey ${ }^{3}$ Department of General Surgery, School of Medicine, Malatya Turgut Ozal University, Malatya, Turkey

${ }^{4}$ Department of General Surgery, Elazı ğ Medical Park Hospital, Elazığ, Turkey

Submitted: 24 April 2021

Accepted: 20 June 2021

Arch Med Sci Civil Dis 2021; 6: e75-e77

DOI: https://doi.org/10.5114/amscd.2021.107846

Copyright $\odot 2021$ Termedia \& Banach

\section{Abstract}

Introduction: We aimed to evaluate the effect of stump ligation techniques on operative time in laparoscopic appendectomy.

Material and methods: The patients who underwent laparoscopic appendectomy in our General Surgery Clinic between January 2016 and August 2018 were retrospectively reviewed. The effects of stump ligation techniques used in the operations on operative times were evaluated.

Results: Sixty consecutive patients were screened and 3 groups, 20 patients in each group, were formed based on stump ligation techniques. Extracorporeal knotting - loop ligation was used in Group 1; intracorporeal knotting was used in the Group 2; hem-o-lok clip was used in Group 3.There was no statistically significant difference between the groups in terms of gender distribution and mean age. However, there was a significant difference between the hem-o-lok clip group (Group III) and the intracorporeal knot group (Group II) in terms of operative time. Group III had a shorter operative time. The Group III patients had the shortest operative time, while the Group II patients had the longest operative time $(p<0.05)$.

Conclusions: We can speculate that hem-o-lok clip among the stump ligation techniques reduces the cost, is a safe method and shortens the operative time. However, prospective randomized studies with a large sample size comparing different techniques are needed to determine the ideal treatment procedure. At the same time, stapler use may be considered in cases where the base of the appendix is too inflamed or necrosed. It is known that the use of a stapler and endoloop is more expensive than all other techniques. However, the most important issue for the surgeon is patient safety; therefore the most appropriate technique should be preferred.

Key words: laparoscopic appendectomy, operative time, stump ligation.

\section{Introduction}

Appendectomy is the most commonly performed surgical procedure in general surgery clinics. The first known appendectomy was reported by Cladius Amyand in 1736; however, it has been routinely performed after the classical appendectomy was fully described by McBurney in the $19^{\text {th }}$ century. On the other hand, laparoscopic appendectomy was described by Semm in the early 1980s, approximately 250 years after the description of classical appendectomy [1, 2].

\author{
Corresponding author: \\ Serhat Doğan \\ Department of \\ General Surgery \\ School of Medicine \\ Malatya Turgut \\ Ozal University \\ Malatya, Turkey \\ Phone: +90 5069306797 \\ E-mail: drserhatdogan@ \\ gmail.com
}


There are numerous studies comparing laparoscopic appendectomy with open appendectomy. Both have advantages and disadvantages. Laparoscopy has lower risk of incisional surgical site infection, shorter length of hospital stay and faster return to work, but prolonged operative time and high cost [3].

In the early periods of laparoscopic surgery, operative time was quite long, whereas it gradually decreased as both medical technology and the experience of surgeons developed. Nevertheless, the operative time of laparoscopic appendectomy in uncomplicated patients is given as about 5080 min $[4,5]$. The most time-consuming phase in laparoscopic appendectomy is the phase of secure ligation of the appendix stump. Techniques such as the use of staplers, extracorporeal knotting - loop ligation, intracorporeal knotting, and hem-o-lok clip have been described for stump ligation $[6,7]$.

The aim of this study was to investigate the effect of stump ligation techniques on operative time of laparoscopic appendectomy in uncomplicated patients.

\section{Material and methods}

The patients on whom laparoscopic appendectomy was performed by the same surgeon with the diagnosis of acute appendicitis in our General Surgery Clinic between January 2016 and August 2018 were retrospectively reviewed. The data were obtained from personal records and computer records. The required permissions were obtained from the hospital administration and informed consent was obtained from all patients.

The study included patients who were identified to be uncomplicated during the exploration. Consecutive patients were screened and were divided into 3 groups depending on their stump ligation techniques. They were enrolled in extracorporeal knotting - loop ligation (Group 1), intracorporeal knotting (Group 2) and hem-o-lok clip (Group 3) (Figure 1) groups. Twenty consecutive patients were enrolled in each group in the study.

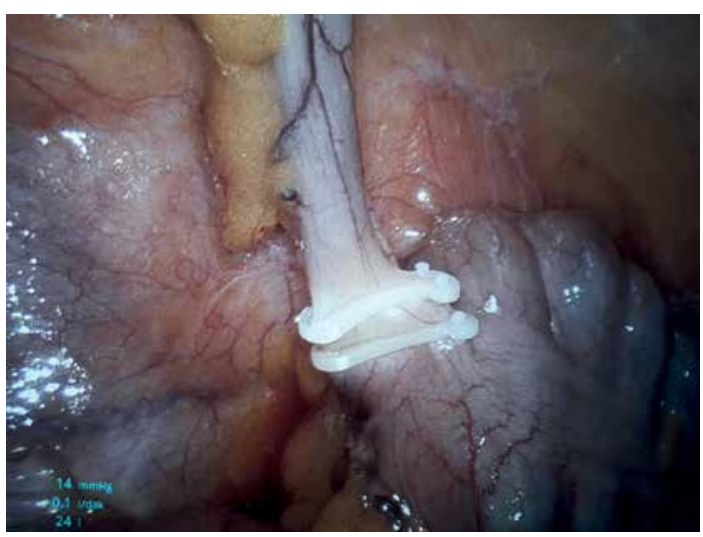

Figure 1. Laparoscopic appendectomy
After 20 consecutive patients operated by the same surgeon were obtained from each group, other patients were not included in the study.

Patients whose data were not complete, those who were considered to be complicated laparoscopy (perforated/abscess/additional pathology/ brid etc.), and patients whose surgery was converted to open surgery were excluded from the study.

\section{Statistical analysis}

The groups were compared in terms of age, gender, and operative time. The $\chi^{2}$ independence test was used to analyze the inclusion values of the patients into the Groups 1, 2 and 3, and the differences between the genders of the patients. The one-way ANOVA test was performed to analyze the differences in age and operative time in terms of the patient groups.

\section{Results}

Sixty patients who underwent operations performed by the same surgeon in our clinic between January 2016 and August 2018 were divided into groups, and then analyzed. In the extracorporeal knotting - loop ligation group (Group 1), the mean age of the patients was 31.6 years, and the female to male ratio was $8 / 12$. The mean operative time of this group was $54 \pm 13 \mathrm{~min}$. In the intracorporeal knotting group (Group 2), the mean age of the patients was 32.8 years, the female to male ratio was $11 / 9$, and the mean operative time was 62 $\pm 11 \mathrm{~min}$. In the hem-o-lok clip group (Group 3), the mean age of the patients was 30.4 years, the female to male ratio was $10 / 10$, and the mean operative time was $49 \pm 10$ minutes (Table I).

There was no statistically significant difference between the groups in terms of gender distribution and mean age. However, there was a significant difference between the hem-o-lok clip group (Group III) and the intracorporeal knotting group (Group II) in terms of operative time. Group III had a shorter operative time. The Group III patients had the shortest operative time, while the Group II patients had the longest operative time $(p<0.05)$.

\section{Discussion}

Although laparoscopy has unique advantages in many fields, its application in appendectomy is still controversial. Despite the fact that laparoscopic cholecystectomy has recently been described, laparoscopic appendectomy could not attain the same common popularity and enthusiasm. Today, laparoscopy has still not become the gold standard for the appendix and is a matter of debate [8]. The advantages of laparoscopic appendectomy include low risk of wound site infection, 
Table I. Characteristics of the groups

\begin{tabular}{|lcccc|}
\hline Parameter & Group I & Group II & Group III & $P$-value \\
\hline$N$ & 20 & 20 & 20 & \\
\hline F/M & $8 / 12$ & $11 / 9$ & $10 / 10$ & $>0.05$ \\
\hline Age & 31.6 & 32.8 & 30.4 & $>0.05$ \\
\hline Operative time & $54 \pm 13$ & $62 \pm 11$ & $49 \pm 10$ & $<0.05$ \\
\hline
\end{tabular}

less postoperative pain, and shorter length of hospital stay. However, it also has drawbacks such as prolonged operative time and high cost.

Stump closure techniques are particularly important in the prolongation of operative time in laparoscopic appendectomy, because safe surgery is of importance, and all surgeons spend the most time at this phase because of the fear of appendiceal stump leak.

Safe closure of the stump is one of the most important steps for safe surgery in appendectomies. At this phase, surgeons have used various techniques to reduce time and increase safety (intracorporeal suturing, use of an endoloop, hem-olok clip, endostapler) $[1,9,10]$.

There is no standard technique for stump closure in laparoscopic appendectomy. In the literature, there are studies on the evaluation of cost, practicability, safety and efficacy of the hem-o-lok clip $[9,11,12]$. The study by Graham et al. has emphasized that polymer clips, which we also use, are safe and effective, but that a stapler should be used in cases where the appendiceal stump is large, gangrenous or perforated and cannot be clipped in $10 \%$ of the patients. Since complicated cases were excluded from the study, there were no problems with the clip in stump closure in this study.

The study by Yildiz et al. [13] compared the stapler, endoloop, hem-o-lok clip and their own stump closure mechanisms, and found no significant difference between the groups in terms of operative time. However, the hem-o-lok clip shortened the operative time in our study. We are of the opinion that this was due to longer administration times of the techniques that we compared, because both the stapler and the endoloop are used without a direct firing mechanism and preparation time.

When the literature is reviewed in the light of these data, we can speculate that the hem-o-lok clip reduces the cost, shortens the operative time, and is also a safe technique according to our study.

As can be seen, there is no technique agreed to be optimal despite the numerous studies. There is a limited number of prospective randomized studies comparing different methods. It is known that the use of a stapler and endoloop is more expensive than all other techniques. However, the most important issue for the surgeon is patient safety; therefore the most appropriate technique should be preferred.

\section{Conflict of interest}

The authors declare no conflict of interest.

\section{References}

1. Semm K. Endoscopic appendectomy. Endoscopy 1983; 15: 59-64.

2. Ferrarese AG, Martino V, Enrico S, et al. Laparoscopic appendectomy in the elderly: our experience. BMC Surg 2013; 13 Suppl 2: S22.

3. Cipe G, Idiz O, Hasbahceci M, et al. Laparoscopic versus open appendectomy: where are we now? Chirurgia 2014; 109: 518-22.

4. Ferrarese AG, Martino V, Enrico S, et al. Laparoscopic appendectomy in the elderly: our experience. BMC Surg 2013; 13 Suppl 2: S22.

5. Phillips S, Walton JM, Chin I, Farrokhyar F, Fitzgerald P, Cameron B. Ten-year experience with pediatric laparoscopic appendectomy: are we getting better? J Pediatr Surg 2005; 40: 842-5.

6. Mehdorn M, Schürmann O, Mehdorn HM, Gockel I. Intended cost reduction in laparoscopic appendectomy by introducing the endoloop: a single center experience. BMC Surg 2017; 17: 80.

7. Parlakgumus A, Ezer A. Polymeric clips for stump closure in laparoscopic appendectomy. J Coll Physicians Surg Pak 2017; 27: 660-2.

8. Minné L, Varner D, Burnell A, Ratzer E, Clark J, Haun W. Laparoscopic vs open appendectomy. Prospective randomized study of outcomes. Arch Surg 1997; 132: 708-11.

9. Varghese G. Feasibility and efficacy of using hem-o-lok polymeric clips in appendicular stump closure in laparoscopic appendectomy. Cureus 2018; 10: e2871.

10. Gupta R, Sample C, Bamehriz F, Birch DW. Infectious complications following laparoscopic appendectomy. Can J Surg 2006; 49: 397-400.

11. Kim S, Weireter L. Cost effectiveness of different methods of appendiceal stump closure during laparoscopic appendectomy. Am Surg 2018; 84: 1329-32.

12. Graham CW, Komidar L, Perger L. Comparison of polymeric clips and endoscopic staplers for laparoscopic appendectomy. J Laparoendosc Adv Surg Tech A 2019; 29: 240-2.

13. Yıldız I, Koca S. Is there an ideal stump closure technique in laparoscopic appendectomy? Surg Technol Int 2016; 28: 117-20. 